\title{
Filling the gaps: the home dialysis discussion
}

\author{
Gurmukteshwar Singh ${ }^{1}[$
}

Received: 18 September 2021 / Accepted: 11 November 2021 / Published online: 9 January 2022

(c) The Author(s) under exclusive licence to Italian Society of Nephrology 2021

Keywords Home dialysis · Home hemodialysis · Peritoneal dialysis · Dialysis education · Dialysis options · Dialysis modality

I'm old, had surgery, too fat, too poor.

I'm deaf. I'm blind. Really need to shower.

Rewiring, replumbing, too much to juggle.

Failed transplant, in-center's already a struggle.

Need to go swimming, travel and roam.

It takes too long, feels unsafe at home.

Too complex, no partner, sounds like a slog.

I'm afraid of needles. What about my dog?

I'll just get infected, alone and needy.

Just get me in-center, not home hemo or PD.

$\mathrm{O}$ my dear patient, don't drown in woe.

These are mere myths, and demonstrably so.

Age or travel are no bar. Infections are few,

With appropriate precautions, you can shower and swim too.

About your concern, a belly scarred and plump,

Innovation and fortitude will win over that hump.

We'll work out finances, pets and home install.

You will be trained well, someone's always on call.

Disabilities or no partner have minor impact.
If still unsure, let me present another fact:

If they need dialysis, what do the experts use?

A home modality, most nephrologists choose.

Gurmukteshwar Singh, MD.

\section{Declarations}

Conflict of interest The author declares that they have no conflict of interest.

Ethical statement This work did not involve human subjects research, hence was exempt from ethics committee review or informed consent.

Publisher's Note Springer Nature remains neutral with regard to jurisdictional claims in published maps and institutional affiliations.

Gurmukteshwar Singh

Geisinger Health, Danville, PA, USA 